\title{
психология
}

DOI: $10.17805 / g g z .2017 .1 .4$

\section{Соотношение тревожности и мотивационных диспозиций у лиц с ограниченными возможностями здоровья \\ О. Е. КОМолов}

МОСКОВСКИЙ ГОСУДАРСТВЕННЫЙ ПСИХОЛОГО-ПЕДАГОГИЧЕСКИЙ УНИВЕРСИТЕТ

В статье проводится краткий обзор и анализ современных исследований по проблеме соотношения тревожности и мотивационных диспозиций у лиц с ОВЗ.

Ключевые слова: тревожность, мотивационные диспозиции, мотивационная сфера личности, ОВЗ.

\section{The correlation of anxiety and motivational dispositions among persons with disabilities \\ O. E. KOMOLOV \\ Moscow State University of PSyChOLOGY AND EDUCATION}

The article presents a review and analysis of modern research on the anxiety and motivational dispositions among persons with disabilities.

Keywords: anxiety, motivational dispositions, motivational sphere of personality, disabilities.

Социализация человека в онтогенезе привела к формированию произвольных психических функций, главной из которых следует назвать деятельность. Аеятельность это внешняя и внутренняя активность человека, регулируемая сознательной целью. Внешняя деятельность - это предметная, материальная деятельность, а внутренняя это деятельность памяти, мышления и т. п. Если рассматривать внешнюю деятельность, то она детерминируется потребностью - нуждой, состоянием напряженности, которая побуждает к поисковой деятельности и в процессе которой находится предмет потребности. Изучение факторов, детерминирующих деятельность, является одним из приоритетных направлений в современной психологической науке.

Одними из таких факторов являются мотивы и мотивация личности. Мотивация представляет собой особый уровень активности человека и определяет готовность личности к деятельности, которая проявляется в соответствующих актах поведения. За рубежом достаточно распространенным является диспозиционный подход к исследованию мотивации, предложенный американским исследователем А. Макклелландом. Аанный автор утверждал, что условно можно выделить четыре мотивационные системы: мотивация власти, аффилиации, достижения и избегания. Наиболее важными представляются именно те диспозиции, которые характеризуют социальную жизнь респондентов: мотивация достижения успеха, боязнь неудачи, стремление к налаживанию контактов с людьми (аффилиация) и боязнь отвержения, поскольку именно они определяют ряд особенностей жизнедеятельности студентов с ОВЗ (ограниченными возможностями здоровья).

Можно сказать, что если каждая из мотивационных диспозиций отражает развитие социальных мотивов человека, то они также имеют противоположные системы, 
которые являются отражением потребности в безопасности. Таким образом, каждая из мотивационных систем, испытывает на себе влияние мотива избегания, который актуализируется, в том числе, в результате воздействия определенных индивидуально-психологических предпосылок, таких, как уровень тревожности. В результате, мотив власти будет выражаться в избегании ответственности, мотив достижения в избегании неудачи, мотив аффилиации - в страхе отвержения.

Одной из потенциальных особенностей личности является тревожность. Аанная особенность занимает важное место среди иных качеств, влияющих на практическую деятельность человека, так как результаты и әффективность этой деятельности нередко напрямую зависят от уровня тревожности субъекта. Тревожность играет важную роль в понимании того, как человек будет выполнять ту или иную деятельность, особенно в том случае, когда эта деятельность имеет социальный или конкурентный подтекст. Проявления тревожности в различных ситуациях не одинаковы. В одних случаях люди склонны вести себя тревожно всегда и везде, в других они обнаруживают свою тревожность лишь время от времени, в зависимости от складывающихся обстоятельств. Ситуативно устойчивые проявления тревожности принято называть личностными и связывать с наличием у человека соответствующей личностной черты. По словам Р. Немова, поведение повышенно тревожных людей в деятельности, направленной на достижение успехов, имеет следующие особенности:

- Высокотревожные индивиды эмоционально острее, чем низкотревожные, реагируют на сообщения о неудаче.

- Высокотревожные люди хуже, чем низкотревожные, работают в стрессовых ситуациях или в условиях дефицита времени, отведенного на решение задачи.

- Боязнь неудачи - характерная черта высокотревожных людей. Эта боязнь у них доминирует над стремлением к достижению успеха.

- Мотивация достижения успехов преобладает у низкотревожных людей. Обычно она перевешивает опасение возможной неудачи.

- Аля высокотревожных людей большей стимулирующей силой обладает сообщение об успехе, чем о неудаче.

- Низкотревожных людей больше стимулирует сообщение о неудаче.

- Аичностная тревожность предрасполагает индивида к восприятию и оценке многих, объективно безопасных ситуаций как таких, которые несут в себе угрозу (Немов Р., 2003).

Проблемы, связанные с влиянием тревожности на мотивационную сферу, значительно усугубляются в отношении тех, кто испытывает трудности полноценной адаптации, интеграции и эффективного социального функционирования, в частности, вследствие ограниченных возможностей здоровья. Общепризнанно считать, что инвалиды (лица с ОВ3) являются одной из самых социально уязвимых и неадаптированных групп населения. Социальная реальность людей с ограниченными возможностями такова, что слабо способствует появлению мотивации к труду. Шансы быть принятыми на работу у инвалидов существенно ниже, чем у здоровых людей, намного меньше имеется мест трудоустройства, но, в то же время, у людей с ограниченными возможностями невысокая удовлетворенность материальным положением зачастую компенсируется мотивацией к его улучшению.

Инвалид - человек, у которого возможности его личной жизнедеятельности в обществе ограничены из-за его физических, умственных, сенсорных или психических отклонений. В данной работе речь идет в первую очередь о лицах с физическими 
ограничениями (нарушения опорно-двигательного аппарата, зрения, слуха и т. А.) и вместо термина «инвалидность» используются формулировка «ограниченные возможности здоровья». Соответственно, термин «условно здоровые лица» (лица без OB3) противоположен термину «инвалидность»и означает отсутствие ограничений личной жизнедеятельности, физических, умственных, сенсорных или психических отклонений.

Поскольку мотивационные диспозиции неизбежно определяют результаты и әффективность деятельности, можно сделать предположение об их взаимосвязи и взаимной зависимости с явлением тревожности. Изучение данной взаимосвязи на примере лиц с инвалидностью позволит понять причины возникновения у них высокой тревожности, обнаружить значимость их эмоциональных переживаний на фоне их социально-коммуникативной деятельности, а также поможет преодолеть ее негативное влияние на успех, оптимизировав образовательную и профессиональную деятельность.

Исследования особенностей тревожности у лиц с ОВЗ в современной науке проводятся, в частности, в рамках диссертационных исследований. Чаще всего ограниченные возможности здоровья в них рассматриваются как один из основных факторов повышенной тревожности. Так, $\Lambda$. Заборина в ходе исследования личностных характеристик и особенностей эмоционального реагирования у лиц с ограниченными возможностями здоровья пришла к выводу о том, что людям с ОВЗ свойственен «Сниженный фон настроения, опечаленность, удрученность своим положением напрямую зависит от уровня тревожности личности. Сниженный фон настроения приводит к учащению вспышек раздражительности у людей с ограниченными возможностями здоровья» (Забродина, 2012). В то же время некоторые исследования опровергают наличие такой взаимосвязи (Комолов О. Е., 2014).

Проблема выраженности мотивационных диспозиций у людей с инвалидностью также не имеет однозначного решения. Так, Н. И. Скок, исследуя биосоциальный потенциал лиц с ОВ3, описывает ход исследования следующим образом: «Опрошено 400 инвалидов и 400 здоровых лиц трудоспособного возраста. Оказалось, что уровень мотивации у тех и других мало отличается. Есть разница лишь в случае избегания неудач. Последнее соответствует данным мотивации у лиц с невротическими расстройствами, каковыми в большинстве своем являются люди с ограниченными возможностями» (Скок, 2005).

Как показала О. Купреева в своем исследовании (Купреева, 2011), студенты с ограниченными возможностями здоровья испытывают потребность в психологической поддержке при решении проблем личностного самоопределения, сохранения и развития психического здоровья, развития социальной активности и личности в целом.

В. Краснова сделала вывод о том, что формирование основных адаптационных стратегий в отношении лиц с ОВЗ тесно связано с преобладающей формой восприятия инвалидности типичными членами данного общества. Иначе говоря, восприятие инвалидов типичными членами социальной среды обусловлено господствующими «идеально-типическими конструкциями» (моделями инвалидности), т. е. обобщенными социокультурными представлениями об инвалидности (Краснова, 2013).

Изучение тревожности и мотивационных диспозиций у лиц с ОВ3 поможет выявить причины их состояния и более эффективно интегрировать их в социальное взаимодействие, учебный и рабочий процесс, сводя их проблемы, связанные с издержками социализации, к минимуму. 


\section{СПИСОК АИТЕРАТУРЫ}

Забродина, А. Г. (2012) Исследование личностных характеристик и особенностей эмоционального реагирования у лиц с ограниченными возможностями здоровья // Ученые записки Забайкальского государственного университета. С. 298-305.

Комолов, О. Е. (2014) Особенности проявления тревожности у студентов с ограниченными возможностями здоровья // Научная и профессиональная идентичность студента. Материалы международной научно-практической студенческой конференции. Рига, 12-13 декабря 2014. Рига: Балтийский институт психологии и менеджмента. С. 294-297.

Краснова, В. В. (2013) Социальная тревожность как фактор нарушений интерперсональных отношений и трудностей в учебной деятельности у студентов: автореферат дис. ... канд. психол. наук : 19.00.13. М. : МГППУ. 26 с.

Купреева, О. И. (2011) Особенности психологического сопровождения студентов с ОВЗ. Инклюзивное образование: методология, практика, технологии: Материалы международной научно-практической конференции (20-22 июня 2011, Москва). М. : МГППУ. 244 с.

Немов, Р. С. (2003) Психология. М. : ВАААОС. Кн. 1. Общие основы психологии. 688 с.

Скок, Н. И. (2005) Биосоциальный потенциал лиц с ограниченными возможностями и социальные механизмы его регуляции // Актуальные проблемы медико-социальной экспертизы и реабилитации инвалидов: Материалы межрегиональной научно-практической конференции. Тюмень. С. 124-127.

Аата обращения: 07.01.2017 г.

Комолов Олег Евгеньевич - магистрант, кафедра педагогики и психологии дистанционного обучения Московского государственного психолого-педагогического университета. Адрес: 127051, Россия, г. Москва, Сретенка 29. Тел.: +7 (495) 607-12-47, +7 (495) 632-99-83. Электронный адрес: fdomgppu@gmail.com.

Komolov Oleg Evgenevich, Master's student, Department of distance learning education and psychology of Moscow State University of Psychology and Education. Address: 127051, Russia, Moscow, 29 Sretenka St. Tel.: +7 (495) 607-12-47, +7 (495) 632-99-83. E-mail: fdomgppu@gmail.com.

\section{Аля цитирования:}

Комолов О. Е. Соотношение тревожности и мотивационных диспозиций у лиц с ограниченными возможностями здоровья [Электронный ресурс]// Горизонты гуманитарного знания. 2017, № 1. URL: http://journals.mosgu.ru/ggz/article/view/443 (дата обращения: дА.мм.гггг.). DOI: $10.17805 /$ ggz.2017.1.4 